УДК 657.01

DOI 10.18101/2304-4446-2019-1-40-48

\title{
БУХГАЛТЕРСКИЙ УЧЕТ КАК СИСТЕМА
}

\author{
(c) Тищенко Марина Анатольевна \\ кандидат экономических наук, доцент, \\ Красноярский государственный аграрный университет \\ Россия, 660049, г. Красноярск, пр. Мира, 90 \\ E-mail: mtischenko@mail.ru
}

\begin{abstract}
Предметом исследования является взаимосвязь и сущность элементов системы бухгалтерского учета как совокупность элементов ее определенных блоков. В статье расширены научные представления о системе бухгалтерского учета, определены ее неотъемлемые части. Представлен авторский взгляд на бухгалтерский учет как систему, разработана комплексная группировка ее составляющих в структурированном единстве в разрезе фундаментального, функционального и регулирующего блоков. Предложенная группировка элементов учета по блокам позволяет рассматривать бухгалтерский учет как целостную систему, представляющую взаимосвязь всех его элементов в едином комплексе.
\end{abstract}

Ключевые слова: бухгалтерский учет; система; элементы; группировка; фундаментальный блок; функциональный блок; регулирующий блок.

\section{Для цитирования:}

Тищенко М. А. Бухгалтерский учет как система // Вестник Бурятского государственного университета. Экономика и менеджмент. 2019. Вып. 1. С. 40-48.

В настоящее время перед руководством любой коммерческой организации стоит задача не только сохранения, но и развития бизнеса. При этом эффективное ведение финансово-хозяйственной деятельности возможно лишь при рациональном управлении, обеспечивающем оперативное выявление и мобилизацию внутренних резервов.

Рациональность любого управленческого решения во многом зависит от информации, предоставляемой бухгалтерским учетом. В связи с этим возрастает роль учета, прежде всего как информационной системы, охватывающей всю финансово-хозяйственную деятельность организации. Следовательно, по нашему мнению, бухгалтерский учет необходимо рассматривать системно, комплексно представляя все его элементы.

Исследование объекта как системы осуществляется с помощью системного подхода, который является одним из направлений методологии научного познания.

Возникновение понятия «система» относится к временам Древней Греции. Тогда его значение было определено как «устройство», «союз», «организация». Кроме того, термин «система» применялся, когда речь шла о чем-либо приведенном в порядок, поставленном вместе. Таким образом, понятие характеризовало упорядоченность и целостность естественных объектов. Как отмечает В. В. Кузнецов, с возникновением науки и философии Возрождения бытие стало истолковываться как система мира. При этом уже тогда система была независимой от человека и обладала собственными законами и структурой [1]. 
В дальнейшем на становление системности бытия значительно повлияло открытие гелиоцентричности системы мира Николаем Коперником (1473-1543). В XV и XVII вв., основываясь на идеях Галилея (1564-1642) и Исаака Ньютона (1642-1727) была выработана концепция систем с категориями: целое и часть, вещь и свойство.

В XVIII в. немецким математиком и философом И. Г. Ламбертом (1728-1777) проводится философский анализ системности научного бытия. Он разработал общую системологию, при этом указывал, что любая наука представляет собой систему как целостную совокупность идей и принципов. Тогда же И. Кант (17241804) предложил рассматривать системность как некую методологию, в которой определены процедуры и средства получения системных научных знаний.

В период XIX-XX вв. возникает необходимость управлять огромными техническими установками, отраслями промышленности, транспортными и информационными коммуникациями и т. д. В связи с этим проводятся исследования системообразующих принципов, повышается роль моделей в познании. В дальнейшем вопросами научного подхода при управлении сложными системами занимался физик А.-М. Ампер (1775-1836).

Российский ученый-экономист А. А. Богданов (1873-1928) подчеркивал необходимость подхода к исследованию любого явления с позиций системности. В 20-х г. XX в. он разработал научную дисциплину тектологию («всеобщую организационную науку»). В своем труде «Всеобщая организационная наука (тектология)» системность он определял как свойство целого быть больше суммы свойств элементов. В ХX в. развивается кибернетика, которая исследует системы любой природы - физической, биологической, экономической, организационной или даже воображаемой.

Л. Берталанфи (1901-1972) развил общую теорию систем. По результатам исследований в 1950 г. он опубликовал книгу «Основы общей теории систем». При этом ученый исследует структурное сходство закономерностей, выявленных в различных дисциплинах. Таким образом, обобщая эти закономерности, появляется возможность выводить общесистемные законы, справедливые для всех рассматриваемых дисциплин.

Большой вклад в исследование систем был внесен бельгийским ученым российского происхождения И. Р. Пригожиным (1917-2003). При исследовании термодинамики неравновесных физических систем ученый пришел к выводу, что выявленные им закономерности справедливы для систем любой природы.

В современной общей теории систем используется общий формальный метод исследования широкого круга специальных систем. Системными исследованиями считается вся совокупность разнообразных специальных научных работ, сходство которых заключается в том, что они рассматривают исследуемые объекты как системы, то есть множества взаимосвязанных составных элементов в виде единого целого.

В XX в. существовало определение системы как множества взаимосвязанных элементов, обособленного от среды и взаимодействующее с ней как целое [2]. Тогда же имело место определение системы как конечного множества функциональных элементов и отношений между ними, выделенного из среды в соответствии с определенной целью в рамках определенного временного интервала [3]. 
В современных условиях также существует большое количество значений термина «система». Многие ученые считают, что термин «система» обозначает как реальные, так и абстрактные объекты и широко используется для образования других понятий (банковская система, денежная система, информационная система, политическая система и др.). Обобщив существующие определения, можно сделать вывод, что система есть совокупность зависимых или независимых элементов, обеспечивающих исполнение целевой функции [1].

Системы имеют ряд свойств, классифицированных по различным признакам. Одно из основных свойств - это иерархичность, которое предполагает, что каждый компонент системы может рассматриваться как система. В свою очередь, сама система может рассматриваться как элемент некоторой надсистемы (суперсистемы). Проецируя это свойство на бухгалтерский учет, очевидно, что будучи системой, он и сам является составной частью системы управления финансовохозяйственной деятельностью. В организациях системой наблюдения, измерения, регистрации и обобщения фактов хозяйственной жизни, явлений, процессов в целях контроля и управления ими является хозяйственный учет.

Место системы бухгалтерского учета в системе хозяйственного учета представлено на рис. 1.

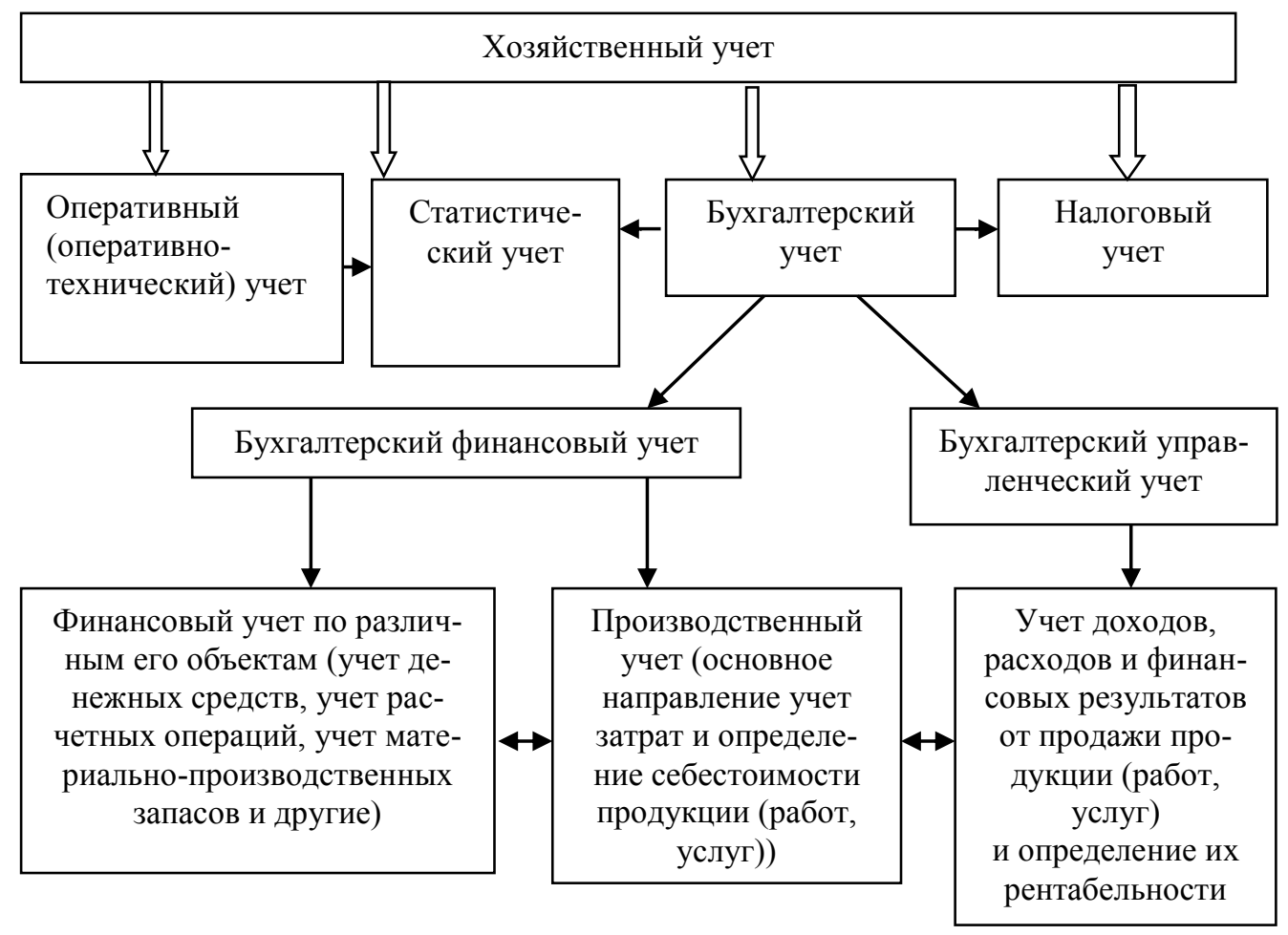

Рис. 1. Место бухгалтерского учета в информационной системе организации

В иерархии хозяйственного учета выделяется четыре вида учета: оперативный или оперативно-технический, статистический, бухгалтерский и налоговый. 
Оперативный учет представляет собой систему регистрации и отражения информации в момент совершения фактов хозяйственной жизни. Этот вид учета позволяет быстро получить сведения о различных хозяйственных явлениях и процессах. Широко используется в подразделениях организации: производственных цехах, бригадах, участках, службах и отделах.

Статистический учет занимается отражением количественной стороны массовых общественных процессов и явлений в неразрывной связи с их качественной характеристикой. Спектр его применения более масштабен по сравнению с оперативным учетом - используется на мировом, государственном уровнях, а также на уровне регионов и хозяйствующих субъектов. Информационной основой для этого вида учета служат данные оперативного и бухгалтерского учета.

В соответствии со статьей 313 главы 25 Налогового кодекса налоговый учет определен как «система обобщения информации для определения налоговой базы по налогу на основе данных первичных документов, сгруппированных в соответствии с порядком, предусмотренным настоящим кодексом»1. При этом налоговый учет тесно связан с бухгалтерским учетом.

Бухгалтерский учет в Федеральном законе «О бухгалтерском учете» определен как «формирование документированной систематизированной информации об объектах, предусмотренных настоящим Федеральным законом, в соответствии с требованиями, установленными настоящим Федеральным законом, и составление на ее основе бухгалтерской (финансовой) отчетности» ${ }^{2}$. Однако, на наш взгляд, бухгалтерский учет, формируя систематизированную информацию, в первую очередь сам является системой, включающей в себя определенную совокупность элементов. В научной экономической и бухгалтерской литературе большинство авторов определяют бухгалтерский учет как систему. Так, М. Д. Акатьева на основе Федерального закона «О бухгалтерском учете» приводит определение бухгалтерского учета как системы, осущзествляющей формирование документированной и систематизированной информации об определенных объектах и обеспечивающей составление на ее основе бухгалтерской (финансовой) отчетности [6].

Любая система может быть разложена на составляющие ее элементы поразному, в зависимости от целей и задач исследования. Целесообразно разделение системы на составляющие компоненты - подсистемы. По нашему мнению, для полного представления совокупности всех элементов системы бухгалтерского учета в структурированном единстве целесообразно их подразделить по следующим подсистемам-блокам - фундаментальному, функциональному и регулирующему (рис. 2). Такое разделение даст возможность исследования как внутренних качеств подсистем, так и процесса их взаимодействия между собой и с внешней средой.

Содержание блоков системы бухгалтерского учета раскрывается элементами, входящими в каждый блок (рис. 3). При представлении системы бухгалтерского учета были выбраны наиболее существенные, по нашему мнению, элементы,

1 Налоговый кодекс Российской Федерации. Ч. 1, 2. Доступ из справ.-правовой системы «КонсультантПлюс».

${ }^{2}$ О бухгалтерском учете: федеральный закон от 6 декабря 2011 г. № 402-Ф3. Доступ из справ.-правовой системы «КонсультантПлюс». 
оказывающие наибольшее влияние на систему. Каждый элемент блока имеет определенные, присущие ему свойства. Совокупность этих свойств определяет состояние элемента. Причем состояние элемента не постоянно, оно может меняться со временем под влиянием эндогенных и экзогенных факторов.

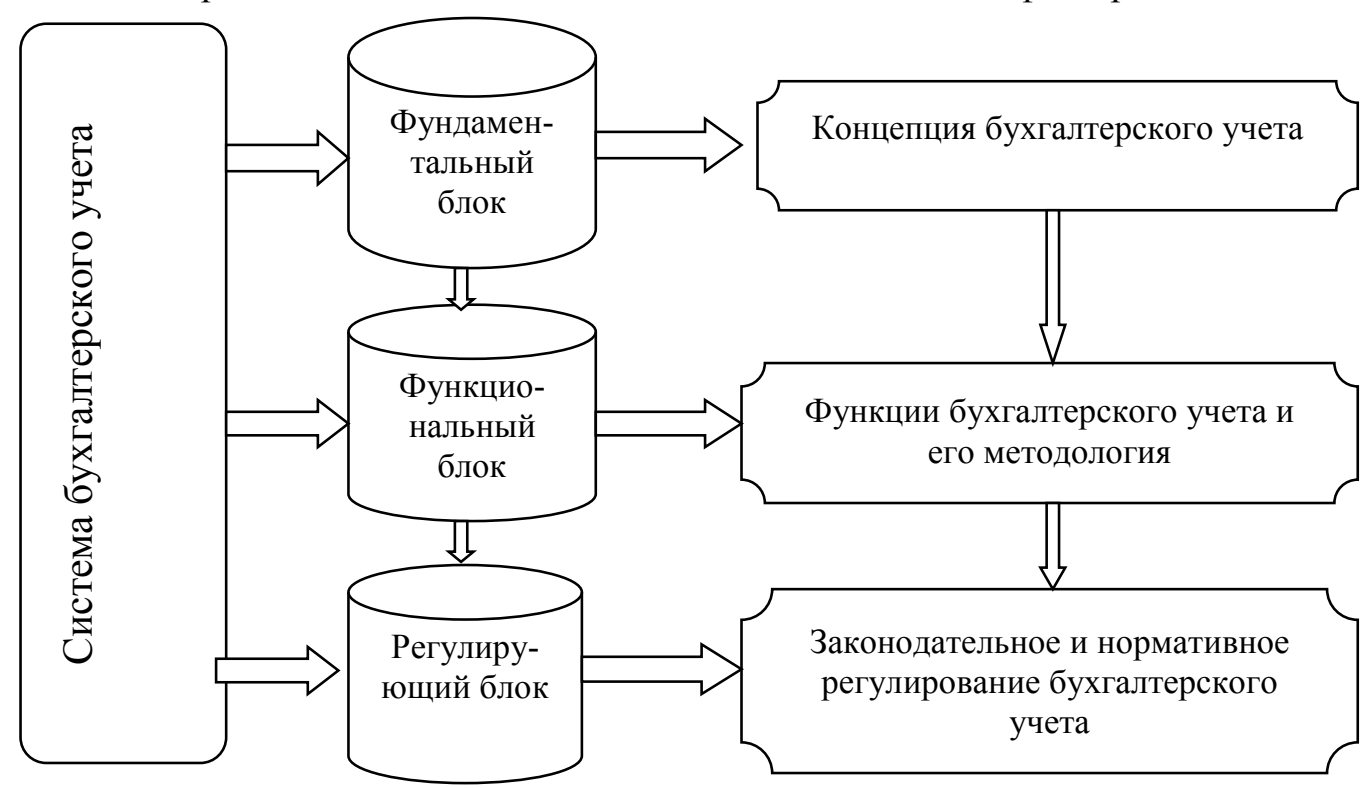

Рис. 2. Предлагаемые блоки системы бухгалтерского учета

Фундаментальный блок, на наш взгляд, определяет саму концепцию бухгалтерского учета. Под концепцией бухгалтерского учета, как считают многие авторы, принято понимать, прежде всего, основные теоретические принципы ведения бухгалтерского учета и отчетности [8].

Фундаментальный блок объединяет в себе такие элементы бухгалтерского учета, как его объекты, цель и задачи, информацию и ее пользователей, а также принципы бухгалтерского учета.

Объекты бухгалтерского учета как элемент системы включают в себя, согласно федеральному закону «О бухгалтерском учете»:

- факты хозяйственной жизни;

- активы;

- обязательства;

- источники финансирования его деятельности;

- доходы;

- расходы;

- иные объекты в случае, если это установлено федеральными стандартами.

Следующий элемент, который предлагается включить в фундаментальный блок, содержащий концепцию бухгалтерского учета, - его цель. Обобщая мнение большинства ученых-экономистов, целью бухгалтерского учета является формирование информации для внутренних и внешних пользователей. Цель бухгалтерского учета определяет его задачи, которые определены положением по ведению бухгалтерского учета и отчетности в Российской Федерации. 
Бухгалтерский учет формирует информацию, необходимую для эффективного управления финансово-хозяйственной деятельностью экономического субъекта, - следующий элемент фундаментального блока. В широком смысле информация представляет собой сведения, данные о каких-либо событиях, явлениях, предметах. Информация бухгалтерского учета содержит сведения о производственно-хозяйственной и финансовой деятельности организаций, которые являются необходимыми при принятии управленческих решений.

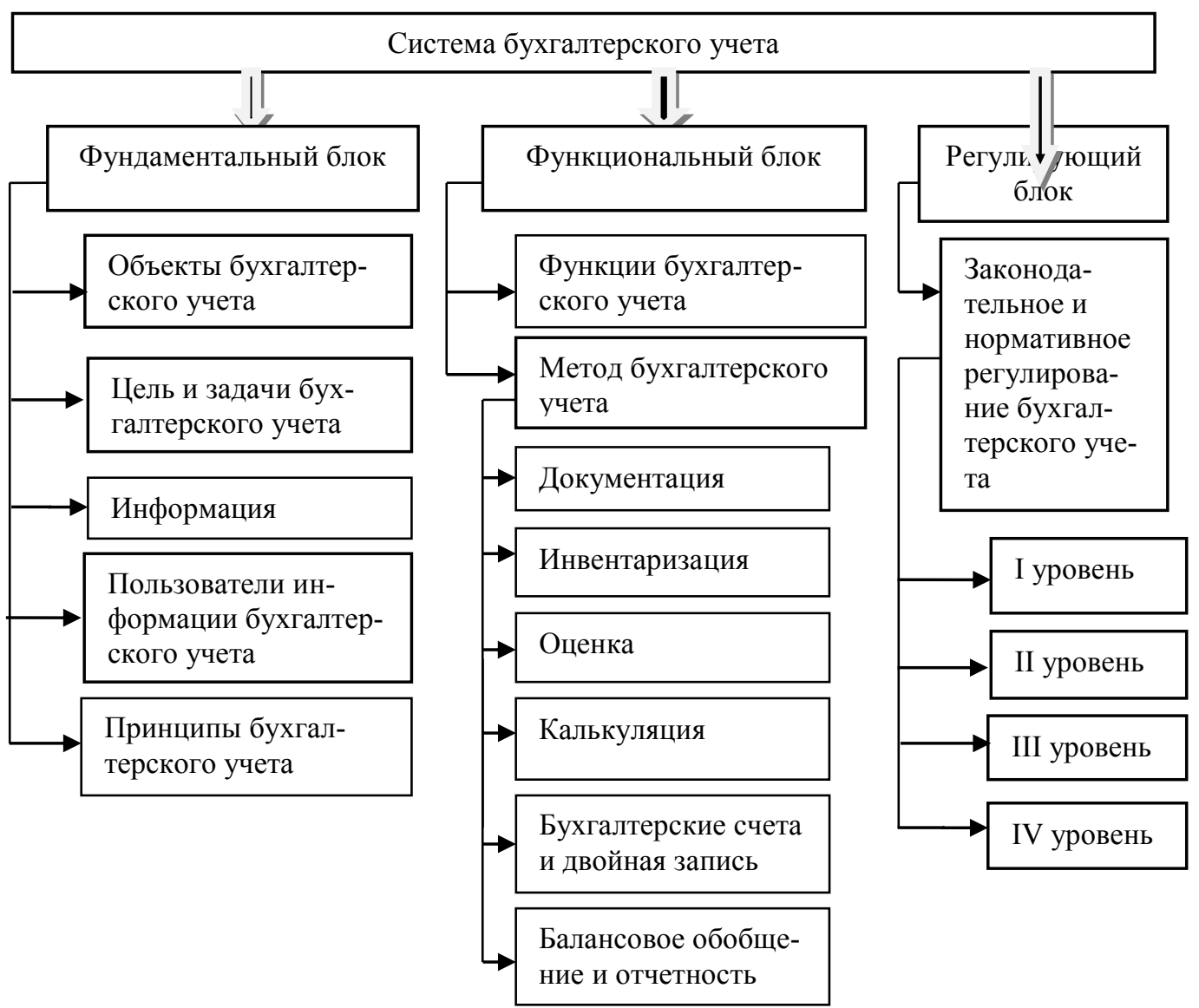

Рис. 3. Система бухгалтерского учета

Любая информация формируется для определенного круга пользователей. Поэтому следующим элементом системы бухгалтерского учета, по нашему мнению, являются внутренние и внешние пользователи его информации. К внутренним пользователям относятся весь административно-управленческий аппарат организации, руководители различных уровней, а к внешним - контрагенты организации (поставщики и покупатели), банки, инвесторы, налоговые органы, государственные внебюджетные фонды, вышестоящие организации, органы статистики, аудиторы и т. д.

Фундаментальный блок также включает такой элемент, как принципы бухгалтерского учета. Принцип — это основное исходное положение какой-либо тео- 
рии, науки, учения. В основе концепции бухгалтерского учета также лежат определенные принципы, которые закреплены нормативными актами Российской Федерации.

Главными правилами, основополагающими бухгалтерскими принципами, отступление от которых не допускается, являются допущения и требования, которые определены положением «Учетная политика организации».

В функциональный блок - следующий компонент системы бухгалтерского учета - нами предлагается включить элементы методологического аспекта бухгалтерского учета: метод, с помощью которого функционирует система бухгалтерского учета, его элементы, а также функиии бухгалтерского учета.

Метод бухгалтерского учета включает в себя совокупность приемов и способов, с помощью которых осуществляется изучение предмета бухгалтерского учета. К таким приемам и способам (элементам метода) относятся документация, инвентаризация, оценка, калькуляция, счета и двойная запись, балансовое обобщение и отчетность.

Документация как прием бухгалтерского учета предполагает оформление фактов хозяйственной жизни первичными документами. Федеральный закон «О бухгалтерском учете» предписывает необходимость оформления первичным учетным документом каждого факта хозяйственной жизни. С помощью первичных документов обеспечиваются также требования полноты учета.

В соответствии с действующими законодательными и нормативными документами обязательным для всех экономических субъектов является проведение инвентаризации активов и обязательств. Помимо сверки фактического наличия имущества и обязательств с учетными данными этот элемент метода позволяет выявить, все ли факты хозяйственной жизни были отражены в документах и системном бухгалтерском учете.

Денежное измерение объектов бухгалтерского учета производится с помощью оценки. Методы и правила оценки различных объектов установлены действующими нормативными документами.

Для определения себестоимости произведенной продукции применяется такой способ, как калькуляция. Структура калькуляции определяет методы и порядок учета производственных затрат, степень их раскрытия в учете, состав плановых показателей и характеристику информации о себестоимости продукции.

Бухгалтерские счета представляют собой способ группировки, текущего контроля и отражения хозяйственных средств организации, источников их образования и хозяйственных процессов. Отражение фактов хозяйственной жизни на счетах бухгалтерского учета производится посредством двойной записи. Этот способ связан с двойственным характером отражения указанных фактов.

Метод балансового обобщения также основывается на двойственном отражении информации об объектах бухгалтерского учета. Как отмечает О. М. Андреева: «как элемент метода бухгалтерского учета балансовое обобщение реализуется в контроле над равновесием данных, формируемых на счетах бухгалтерского учета, служит для увязки этих данных, подтверждает их системное согласование» [7].

Бухгалтерская отчетность является завершающим этапом бухгалтерского учета, на котором производится обобщение учетной информации. Требования к 
систематизации информации бухгалтерской отчетности определены Федеральным законом «О бухгалтерском учете».

Все элементы метода бухгалтерского учета находятся во взаимосвязи и образуют единую систему, которая в рамках системы бухгалтерского учета является компонентом функционального блока.

Следующий компонент функционального блока - функции бухгалтерского учета. В системе управления финансово-хозяйственной деятельностью бухгалтерский учет выполняет информационную, контрольную, аналитическую функции и функцию обратной связи.

Информационная функция предполагает представление бухгалтерской информации руководству предприятия, поставщикам, банкам, налоговым органам и другим пользователям. При этом она обеспечивает интересы и потребность каждого пользователя в полном объеме.

Контрольная функиия осуществляется на разных стадиях деятельности организаций для контроля за рациональным и эффективным использованием материальных, энергетических, трудовых и финансовых ресурсов; формирования полной себестоимости проданной продукции; оценки финансового состояния организации; при составлении финансовой и другой отчетности и т. п.

Аналитическая функиия выражается в том, что бухгалтерская информация используется для анализа финансовой, производственно-хозяйственной деятельности и его подразделений.

Функиия обратной связи означает, что поступившая из первичных бухгалтерских документов информация обрабатывается и используется для принятия управленческих решений. С помощью этой функции все уровни управления организации обеспечиваются необходимой информацией.

Очевидно, что большинство элементов фундаментального и функционального блоков системы бухгалтерского учета действует в жестких рамках законодательного и нормативного регулирования. В результате, по нашему мнению, возникает необходимость выделения в системе бухгалтерского учета третьего компонента - регулирующего блока. В настоящее время в научной литературе выделяются четыре уровня нормативного регулирования бухгалтерского учета в России.

Первыци уровень включает документы, которые регламентируют прямо или косвенно организацию и ведение бухгалтерского учета - законодательные акты, указы президента и постановления Правительства РФ: Гражданский, Налоговый кодекс, федеральные законы и другие акты. Основным актом первого уровня является Федеральный закон «О бухгалтерском учете». Он определяет общие требования к бухгалтерскому учету, его регулирование, положения по хранению документов и т. п.

Ко второму уровню регулирующего блока относятся стандарты - положения по бухгалтерскому учету. Под учетным стандартом принято понимать свод основных правил, устанавливающий порядок учета и оценки определенного объекта бухгалтерского учета или их совокупности.

Третий уровень содержит документы, призванные конкретизировать учетные стандарты в соответствии с отраслевыми и другими особенностями, - методические рекомендации (указания), инструкции, комментарии, письма Минфина РФ и других ведомств. 
Четвертый уровень элементов регулирующего блока представляет собой совокупность документов по бухгалтерскому учету самого экономического субъекта. Они определяют особенности организации и ведения учета в ней. К основным из них можно отнести:

- учетную политику организации;

- первичные документы;

- график документооборота;

- рабочий план счетов бухгалтерского учета;

- формы внутренней отчетности.

Все представленные элементы взаимодействуют, в определенной степени оказывая друг на друга влияние. Таким образом, предложенная группировка элементов учета по блокам позволяет рассматривать бухгалтерский учет как целостную систему, представляющую взаимосвязь всех ее элементов в едином комплексе. При этом обеспечивается база для структурного анализа системы.

\section{Литература}

1. Системный анализ / под общ. ред. В. В. Кузнецова. М.: Юрайт, 2018. 270 с.

2. Сагатовский В. Н. Основы систематизации всеобщих категорий. Томск, 1973.432 с.

3. Перегудов Ф. И., Тарасенко Ф. П. Введение в системный анализ. М.: Высшая школа, $1989.360 \mathrm{c.}$

4. Черняк Ю. И. Системный анализ в управлении экономикой. М.: Экономика, 1970. 151 с.

5. Акатьева М. Д. Исторические аспекты формирования учетных парадигм и их современная оценка // Международный бухгалтерский учет. 2017. Т. 20, № 19. С. 11041114.

6. Акатьева М. Д. Современное уточнение классификации объектов бухгалтерского учета // Международный бухгалтерский учет. 2016. № 8. С. 15-26.

7. Андреева О. М. Элементы метода современного бухгалтерского учета: баланс и балансовое обобщение // Бухгалтерский учет. 2015. № 9. С.123-124.

8. Луканина А. В. Теоретические подходы к формированию учетной политики организации // Международный бухгалтерский учет. 2015. № 48. С.15-35.

\section{ACCOUNTANCY AS A SYSTEM}

\section{Marina A. Tischenko}

Cand. Sci. (Econ.), A/Prof.,

Krasnoyarsk State Agrarian University

90 Mira Prospect, Krasnoyarsk 660049, Russia

E-mail: mtischenko@mail.ru

The subject of investigation is the correlation and essence of the components of accounting system as a set of elements of its specific blocks. The article expands the scientific understanding of the accounting system, identifies its integral elements.

We have presented our own view on accounting as a system, developed a comprehensive grouping of its elements in a structured unity broken down by fundamental, functional and regulatory blocks. The proposed grouping allows us to consider accountancy as an integral system of the interrelated elements.

Keywords: accountancy; system; elements; grouping; fundamental block; functional block; regulating block. 